\title{
Rescheduling Proụek Pembangunan Jembatan Palu V Menggunakan Microsoft Project
}

\author{
Aslam $^{\mathrm{a} *}$ dan T.M. Kamaludin ${ }^{\mathrm{a}}$ \\ ${ }^{a}$ Jurusan Teknik Sipil, Fakultas Teknik Universitas Tadulako, Jl. Soekarno-Hatta Km 9, Palu 94118, Indonesia \\ *Corresponding author's e-mail: haslamms212@gmail.com
}

Received: 12 January 2021; revised: 23 February 2021; accepted: 25 February 2021

\begin{abstract}
One form of project planning is Project scheduling. Project scheduling is one of the elements of Project planning results, which can provide information on the relationship of each other activity to the entire project, the identification of relationships that must be precedence between activities, showing realistic cost and time estimates for each activity on project completion. In this research the author plans to process project work activity of the Palu V Bridge development by limiting its job stage to the quality of concrete work of FC ' $30 \mathrm{MPa}$ for the building over the floor plate. This type of research is analytic. Data collection in the form of secondary data such as schedule and $\mathrm{RAB}$ is done by requesting directly the required data to the relevant party. Then conducted initial schedule evaluation, followed by using Microsoft Project 2019 tool as processing result of the project Process Bridge Hammer V. From the results of the study it was concluded that process use Microsoft Project 2019 requiring a duration of 199 working days. While the scheduling is carried out in the field, the executor requires a duration of 366 working days and the planned scheduling of the implementing party takes 167 working days. If compared to the results of scheduling time duration with the implementation of the field and the duration of the execution planner, the results obtained by the researcher more than 167 days from the time of implementation in the field and slower 32 days from the duration of the planning time.
\end{abstract}

Keywords: scheduling, project, Microsoft Project.

\begin{abstract}
Abstrak: Salah satu bentuk dari perencanaan proyek adalah penjadwalan proyek. Penjadwalan proyek merupakan salah satu elemen dari hasil perencanaan proyek, yang dapat memberikan informasi berupa hubungan tiap kegiatan lainnya terhadap keseluruhan proyek, pengidentifikasian hubungan yang harus didahulukan di antara kegiatan, menunjukan perkiraan biaya dan waktu yang realistis untuk tiap kegiatan pada penyelesaian proyek. Dalam Penelitian ini penulis merencanakan untuk Rescheduling aktivitas pekerjaan proyek Pembangunan Jembatan Palu V dengan membatasi tahapan pekerjaannya hingga pada tahap pekerjaan beton mutu fc'30MPa untuk bangunan atas pelat lantai. Jenis penelitian ini bersifat analitik. Pengumpulan data berupa data sekunder seperti jadwal dan RAB dilakukan dengan meminta langsung data yang dibutuhkan kepada pihak yang terkait. Kemudian dilakukan evaluasi jadwal awal, dilanjutkan dengan menggunakan alat bantu Microsoft Project 2019 sebagai pemrosesan hasil dari Rescheduling Proyek Jembatan Palu V. Dari hasil penelitian ini disimpulkan bahwa Rescheduling menggunakan Microsoft Project 2019 memerlukan durasi waktu 199 hari kerja. Sedangkan penjadwalan yang terlaksana di lapangan, pelaksana memerlukan durasi waktu 366 hari kerja dan penjadwalan yang direncanakan pihak pelaksana memerlukan waktu 167 hari kerja. Jika dibandingkan hasil penjadwalan durasi waktu dengan pihak pelaksanaan dilapangan dan durasi waktu perencana pelaksana, maka hasil yang didapatkan peneliti lebih cepat 167 hari dari waktu pelaksanaan dilapangan dan lebih lambat 32 hari dari durasi waktu perencanaan.
\end{abstract}

Kata kunci: penjadwalan, proyek, Microsoft Project.

\section{Pendahuluan}

Pemerintah Republik Indonesia khususnya Kota Palu terus berupaya membuat pembangunan sarana prasarana untuk mewujudkan kesejahteraan masyarakat. Jembatan merupakan salah satu sarana prasarana yang sangat membantu dalam pengembangan wilayah. Di Kota Palu sendiri telah memiliki beberapa jembatan yakni Jembatan I, Jembatan II, Jembatan III dan Jembatan IV, tetapi Jembatan IV mengalami kerusakan yang diakibatkan bencana sehingga jembatan ini sudah tidak dapat digunakan lagi.

Infrastruktur ini sangat vital berkorelasi positif terhadap perkembangan wilayah di Kota palu, salah satu bentuk perwujudan korelasi positif adalah dilaksanakannya lagi pembangunan jembatan yakni jembatan Palu V. Paket pembangunan jembatan Palu V ini pendanaannya berasal dari Anggaran Pendapatan Belanja Daerah (APBD) Tahun Anggaran 2019.
Untuk dapat melaksanakan suatu paket pembangunan seperti pada proyek pembangunan jembatan Palu V ini memerlukan suatu manajemen proyek. Definisi dari manajemen proyek sendiri adalah suatu kegiatan merencanakan, mengorganisasikan, mengarahkan, mengawasi serta mengendalikan sumber daya organisasi perusahaan guna mencapai tujuan tertentu dalam waktu tertentu dengan sumber daya tertentu [1-2]. Sementara definisi dari proyek sendiri adalah suatu rangkaian aktivitas yang mempunyai titik awal dan titik akhir tertentu yang dilaksanakan individu atau organisasi untuk memenuhi tujuan berdasarkan parameter waktu, biaya dan kinerja yang didefinisikan [3-5]. Tantangan utama dalam melaksanakan suatu proyek ialah mencapai sasaran dan tujuan dengan menyadari adanya batasan-batasan waktu pekerjaan dan anggaran pekerjaan [6]. 
Dalam hal ini maka penjadwalan proyek harus sangat diperhatikan agar dapat mengendalikan waktu dan anggaran pekerjaan yang logis. Penjadwalan proyek dibuat agar mengetahui urutan pekerjaan bagian mana yang harus dikerjakan terlebih dahulu. Penjadwalan dimaksudkan untuk memudahkan dalam melakukan setiap aktivitas agar dilakukan dengan berurut dan tepat waktu. Maka dari itu, setiap proyek harus memiliki jadwal agar setiap pekerjaan dapat berjalan dengan lancar dan mencapai tujuan yang disepakati. Pada pelaksanaan Jembatan Palu V penjadwalan proyek mengalami keterlambatan dari durasi waktu yang direncanakan, sehingga penulis mencoba merescheduling kembali durasi waktu dengan menggunakan sumber daya yang sama dengan pelaksanaan [7-8].

Pada penelitian ini penulis menggunakan perangkat lunak (software) Microsoft Project sebagai penunjang tugas akhir ini dalam melakukan penjadwalan proyek, sehingga diharapkan dapat mempermudah dalam melakukan perencanaan penjadwalan maupun dalam melakukan pemantauan terhadap progress pelaksanaan project di lapangan. Penelitian ini bertujuan untuk mendapatkan durasi waktu setelah menggunakan Microsoft Project pekerjaan beton mutu fc' $30 \mathrm{MPa}$ untuk bangunan atas pelat lantai Jembatan Palu V dan mengetahui perbandingan durasi waktu antara jadwal perencanaan, realisasi pekerjaan dilapangan dan durasi waktu menggunakan Microsoft Project pekerjaan beton mutu fc'30 MPa untuk bangunan atas pelat lantai Jembatan Palu V.

\subsection{Manajemen dan Penjadwalan Proyek}

Menurut Wijaya (2010), manajemen adalah suatu ilmu pengetahuan tentang seni memimpin organisasi yang terdiri dari kegiatan perencanaan, pengorganisasian, pelaksanaan dan pengendalian terhadap sumber daya yang terbatas dalam usaha mencapai tujuan dan sasaran yang efektif dan efisien [9]. Tujuan manajemen adalah mendapatkan metode atau cara teknis yang paling baik, agar dengan sumber sumber daya yang terbatas diperoleh hasil maksimal dalam hal ketepatan, kecepatan, penghematan dan keselamatan kerja secara komprehensif

Penjadwalan proyek merupakan salah satu elemen hasil perencanaan yang dapat memberikan informasi tentang jadwal rencana dan kemajuan proyek dalam hal kinerja sumber daya berupa biaya, tenaga kerja, peralatan dan material serta rencana durasi proyek dan progres waktu untuk penyelesaian proyek [10].

\subsection{Metode Network Diagram}

Ada beberapa macam metode analisi jaringan kerja yang dapat digunakan dalam penjadwalan waktu proyekm antara lain: Critical Path Methode (CPM), Precedence Diagram Methode (PDM), dan Project Evaluation and Review Technique (PERT). PDM merupakan jaringan kerja yang termasuk klasifikasi AON (Activity On Node), dimana kegiatan ditulis dengan noda dan anak panah sebagai penunjuk antara kegiatan-kegiatan yang bersangkutan dalam PDM terdapat pekerjaan tumpang tindih (overlapping), sehingga dalam PDM tidak mengenal istilah kegiatan semu (dummy) [11].

Dalam PDM kotak (node) menandai suatu kegiatan sehingga harus dicantumkan identitas kegiatan dan kurun waktu (durasi) sedangkan peristiwa merupakan ujung setiap kegiatan. Setiap node mempunyai dua peristiwa yaitu peristiwa awal dan akhir. Ruangan dalam noda dibagi menjadi bagian-bagian kecil yang berisi keterangan dari kegiatan antara lain: kurun waktu kegiatan (D), identitas kegiatan (nomor dan nama), mulai dan selesainya kegiatan ES (Earliest Start), LS (Latest Start), EF (Earliest Finish), dan LF (Latest Finish) [12]

Metode ini sering digunakan pada software komputer dan mempunyai karakteristik yang agak berbeda dengan metode Activity On Arrow Diagram yaitu [13]:

1) Pembuatan diagram network dengan menggunakan simpul/node untuk menggambarkan kegiatan.

2) Float, waktu tenggang maksimum dari suatu kegiatan

a) Total Float adalah float pada kegiatan : LF - ES Durasi

b) Relation Float (RF), float pada hubungan keterkaitan

$$
\begin{aligned}
& \mathrm{FS}, \mathrm{RF}=\mathrm{LSj}-\mathrm{EFi}-\text { Lead, } \\
& \mathrm{SS}, \mathrm{RF}=\mathrm{LSj}-\mathrm{ESi}-\text { Lag } \\
& \mathrm{FF}, \mathrm{RF}=\mathrm{LFj}-\mathrm{EFi}-\text { Lead, } \\
& \mathrm{SF}, \mathrm{RF}=\mathrm{LFj}-\mathrm{ESi}-\text { Lag }
\end{aligned}
$$

3) Lag, jumlah waktu tunggu dari suatu periode kegiatan j terhadap kegiatan i telah dimulai, pada hubungan SS dan SF.

4) Lead, jumlah waktu yang mendahuluinya dari suatu periode kegiatan $\mathrm{j}$ sesudah kegiatan i belum selesai, pada hubungan FS dan FF.

5) Dangling, keadaan dimana terdapat beberapa kegiatan yang tidak mempunyai kegiatan pendahulu (predecessor) atau kegiatan yang mengikuti (successor). Agar hubungan kegiatan tersebut tetap terikat oleh satu kegiatan, dibuatkan dummy finish dan dummy start. Berikut ini merupakan hubungan keterkaitan antar kegiatan PDM (Gambar 1- Gambar 4).

a) FS (Finish to Start) : Mulainya suatu kegiatan bergantung pada selesainya kegiatan pendahulunya, dengan waktu mendahului lead.

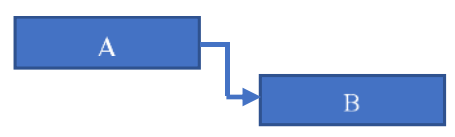

Gambar 1. Grafik jenis hubungan antar pekerjaan Finish to Start

b) SS (Start to Start) : Mulainya suatu kegiatan bergantung pada mulainya kegiatan pendahulunya, dengan waktu tunggu lag.

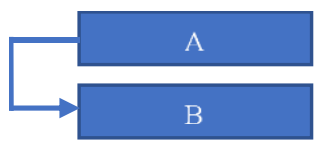

Gambar 2. Jenis hubungan antar pekerjaan Start to Start

c) FF (Finish to Finish) : Selesainya suatu kegiatan bergantung pada selesai kegiatan pendahulunya, dengan waktu mendahului lead. 


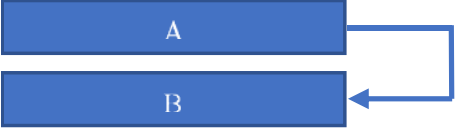

Gambar 3. Jenis hubungan antar pekerjaan Finish to Finish

d) SF (Start to Finish) : Selesainya suatu kegiatan bergantung pada mulainya kegiatan pendahulunya, dengan waktu tunggu lag.

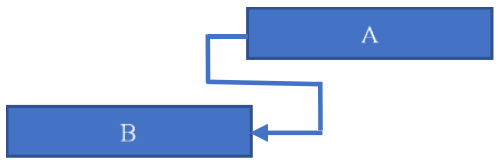

Gambar 4. Jenis hubungan antar pekerjaan Start to Finish

\subsection{Microsoft Project}

Microsoft project merupakan suatu aplikasi populer yang digunakan untuk mengelola proyek, digunakan untuk melakukan perencanaan, pengelolaan, pengawasan dan pelaporan data dari suatu proyek. Kemudahan penggunaan dan keleluasaan lembar kerja serta cakupan unsur-unsur proyek menjadikan software ini sangat mendukung proses administrasi sebuah proyek [14].

Microsoft project merupakan software yang dapat digunakan untuk membuat rancangan proyek serta melakukan manajemen dalam proyek tersebut. Kelengkapan fasilitas dan kemampuannya yang luar biasa dalam pengolah data data proyek menjadikan software ini paling banyak dipakai oleh operator komputer ini karena keberadaannya benar-benar mampu membantu dan memudahkan pemakai dalam menyelesaikan pekerjaan, terutama pekerjaan yang berhubungan dengan data data proyek [15]

\section{Metode Penelitian}

\subsection{Data}

Penelitian ini dilakukan berdasarkan data pada proyek pembangun Jembatan Palu $\mathrm{V}$ yang di bangun melintang Sungai Palu yang akan menjadi penghubung Jl. Anoa 2 Kelurahan Tatura Selatan dan Jl. Jati Kelurahan Nunu.

\subsection{Metode Pelaksanaan}

Metode pengumpulan data yang penulis lakukan adalah dengan cara mengumpulkan data sekunder seperti: jadwal rencana dan $\mathrm{RAB}$, yang dilakukan dengan meminta langsung data yang dibutuhkan kepada pihak terkait (Pelaksana Pembangunan Proyek Jembatan Palu V). pelaksanaan penelitian seperti pada bagan alir (Gambar 5).

\section{Hasil dan Pembahasan}

\subsection{RAB Volume dan Harga Satuan}

Dengan melakukan perhitungan RAB didapatkan volume dan harga satuan dari tiap pekerjaan setelah didapatkan nya volume dan harga satuan maka langkah selanjutnya adalah menghitung jumlah biaya setiap pekerjaan, adapun dalam perhitungan biaya setiap pekerjaan dapat menggunakan Persamaan 5.
Jumlah Biaya $=H S * V$

dengan : $H S=$ harga satuan dan $V=$ volume pekerjaan. Berikut contoh perhitungan RAB Volume dan Harga Satuan: Jumlah Biaya Galian Biasa $=27,941.34 \times 223=$ Rp. 6,230,918.35

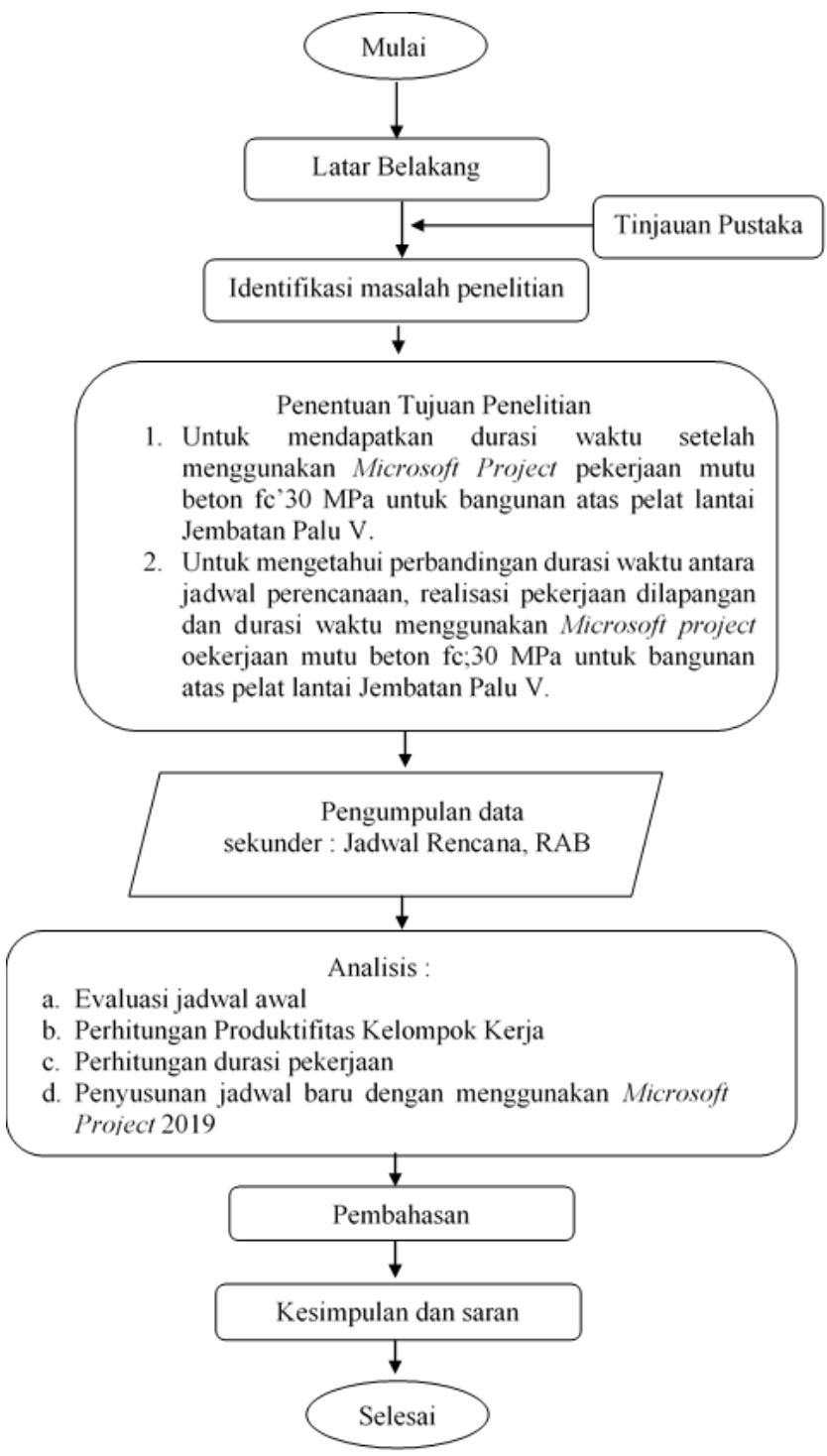

Gambar 5. Bagan alir penelitian

\subsection{Jumlah Biaya Setiap Pekerjaan}

Setelah diperoleh jumlah biaya setiap pekerjaan dan nilai proyek maka langkah selanjutnya menghitung adalah menghitung bobot pekerjaan. Nilai bobot pekerjaan masingmasing nya dihitung dengan menggunakan Persamaan 6.

$$
\text { Bobot }(\%)=\frac{\text { Jumlah Biaya Setiap Pekerjaan }}{\text { Nilai Proyek }} \times 100 \%
$$

Berikut contoh perhitungan jumlah biaya setiap pekerjaan. Bobot Galian biasa $=\frac{6,230,918.35}{39,266,013,800.62} \times 100 \%=$ $0.016 \%$

\subsection{Produktifitas Pekerjaan}

Menghitung produktifitas pekerjaan dalam sehari, dimana pada proyek pembangunan Jembatan Palu $\mathrm{V}$ ini memiliki jam kerja selama 7 jam untuk perharinya, dalam 
perhitungan produktifitas diperlukan produktifitas/jam dan untuk persamaan yang digunakan tiap pekerjaan masingmasing nya tergantung dari peralatan utama yang digunakan untuk mengerjakan tiap pekerjaan tersebut, berikut ini merupakan salah satu contoh perhitungan pekerjaan galian biasa dengan perlatan utama Excavator, persamaan yang digunakan untuk perhitungan ini adalah persamaan berikut:

$$
\mathrm{Q} 1=(\mathrm{V} \times \mathrm{Fb} \times \mathrm{Fa} \times 60) /(\mathrm{Ts} \times \mathrm{Fk})
$$

dengan :

$\mathrm{Q}_{1}=$ Kapasitas produksi/jam $\left(\mathrm{mM}^{3}\right)$

$\mathrm{V}=$ Kapasitas bucket $\left(\mathrm{m}^{3}\right)$

$\mathrm{Fb}=$ Faktor bucket

$\mathrm{Fa}=$ Faktor efisiensi alat

$\mathrm{Fk}=$ Faktor pengembangan bahan

Ts = Waktu siklus menggali, memuat, berputar, dan lainlain (Menit)

\subsection{Durasi Pekerjaan}

Untuk menghitung durasi pekerjaan digunakan data hasil dari produktivitas alat kerja dalam sehari serta volume dari pekerjaan tersebut, dan untuk persamaan yang digunakan untuk menghitung durasi pekerjaan adalah persamaan, sebagai berikut:

$$
\text { Durasi }=\frac{V}{Q t}
$$

dengan:

$\mathrm{V}=$ Volume pekerjaan

$\mathrm{Qt}=$ Produktivitas pekerjaan/hari

Berikut ini merupakan beberapa contoh perhitungan durasi untuk pekerjaan timbunan biasa dari sumber galian dengan produktivitas : 158,921 $\mathrm{m}^{3} /$ hari dan volume: $862,86 \mathrm{~m}^{3}$ : Durasi $=\frac{862,86}{158,86}=5,43$ Hari $\approx 6$ Hari

Tabel 1. Rekapitulasi durasi pekerjaan jembatan (bangunan atas)

\begin{tabular}{llcr}
\hline No. & \multicolumn{1}{c}{ Nama Pekerjaan } & $\begin{array}{c}\text { Durasi } \\
\text { (hari) }\end{array}$ & $\begin{array}{c}\text { Durasi } \\
\text { yang } \\
\text { digunakan } \\
\text { (hari) }\end{array}$ \\
\hline 1 & Divisi 1 Umum & & \\
\hline 2 & Divisi 2 Drainase & 76.47 & 77.00 \\
\hline 3 & $\begin{array}{l}\text { Divisi 3 Pekerjaan } \\
\text { Tanah }\end{array}$ & 66.29 & 70.00 \\
\hline 4 & $\begin{array}{l}\text { Divisi 4 Pelebaran } \\
\text { Pekerasan dan Bahu } \\
\text { Jalan }\end{array}$ & 0.57 & 1.00 \\
\hline 5 & $\begin{array}{l}\text { Divisi 5 Pekerasan } \\
\text { Berbutir }\end{array}$ & 2.08 & \\
\hline 6 & Divisi 7 Struktur & 1919.03 & 1932.00 \\
\hline 7 & $\begin{array}{l}\text { Divisi 8 Pengembalian } \\
\text { Kondisi Dan Pekerjaan } \\
\end{array}$ & 7.45 & 13.00 \\
\hline 8 & $\begin{array}{l}\text { Dinor } \\
\text { Lainisi 9 Pekerjaan }\end{array}$ \\
\hline
\end{tabular}

Dalam penjadwalan untuk pekerjaan timbunan biasa dari sumber galian didapatkan durasi selama 6 hari berdasarkan hitungan dari volume pekerjaan dan produktivitas pekerjaan. Untuk mempermudah dalam perhitungan maka digunakan Microsoft Excel 2019 untuk menghitung durasi dari keseluruhan pekerjaan, dapat dilihat pada Tabel 1 .

\subsection{Penjadwalan dengan Microsoft Project}

Setelah didapatkan durasi untuk masing-masing pekerjaan, maka langkah selanjutnya dengan menggunakan Microsoft Project. Dalam melakukan rescheduling ini digunakan Microsoft Project 2019. Dalam pembuatan rescheduling ada beberapa tahapan yang harus dilakukan

1) Menentukan awal mulai proyek

2) Mengatur penanggalan dan jam kerja

3) Memasukan data task shift

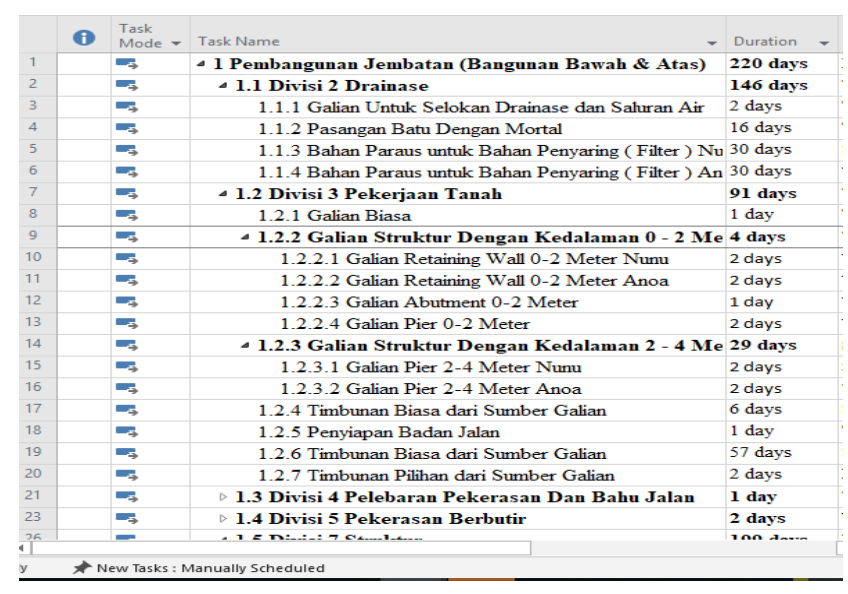

Gambar 6. Tampilan Task Sheet

Tabel 2. Hubungan ketergantungan Divisi 2 Drainase (contoh)

\begin{tabular}{clc}
\hline ID & \multicolumn{1}{c}{ Pekerjaan } & Predecessors \\
\hline 2 & Divisi 2 Drainase & \\
\hline 3 & $\begin{array}{l}\text { Galian untuk selokan drainase } \\
\text { dan saluran air }\end{array}$ & 104,106FS \\
\hline 4 & Pasangan batu dengan mortal & $3 \mathrm{FS}$ \\
\hline 5 & $\begin{array}{l}\text { Bahan paraus untuk bahan } \\
\text { penyaring (filter) Nunu }\end{array}$ & $42,85 \mathrm{FF}$ \\
\hline 6 & $\begin{array}{l}\text { Bahan paraus untuk bahan } \\
\text { penyaring (filter) Anoa }\end{array}$ & $43,82 \mathrm{FF}$ \\
\hline
\end{tabular}

Setelah mengatur penanggalan dan jam kerja selanjutnya kembali kembali ke lebar kerja awal untuk mengisi kolom Task sheet. Data yang diisi berupa

1) Diisikan jenis-jenis pekerjaan pada kolom task name dan waktu kegiatan diisi pada kolom duration, seperti yang terlihat pada Gambar 6.

2) Kolom Start diisi dengan tanggal mulai suatu item pekerjaan dan kolom finish akan terisi secara otomatis. Hal ini akan terjadi apabila pada Project Information dipilih dasar perhitungan Project Start Date.

3) Masukkan hubungan ketergantungan "sebelum" pada kolom Predecessor (aktivitas pendahulu). Dari rencana penjadwalan proyek pembangunan Jembatan Palu V yang dibuat dengan Microsoft Project, hubungan ketergantungan pada kolom Predecessor khususnya Divisi 2 Drainase dapat dilihat pada Tabel 2. Setelah mengisi durasi pekerjaan dan menyusun predecessors, maka hasil dari penginputan data di tampilkan di gantt 
chart untuk tampilan keseluruhan dapat dilihat pada

Gambar 7.

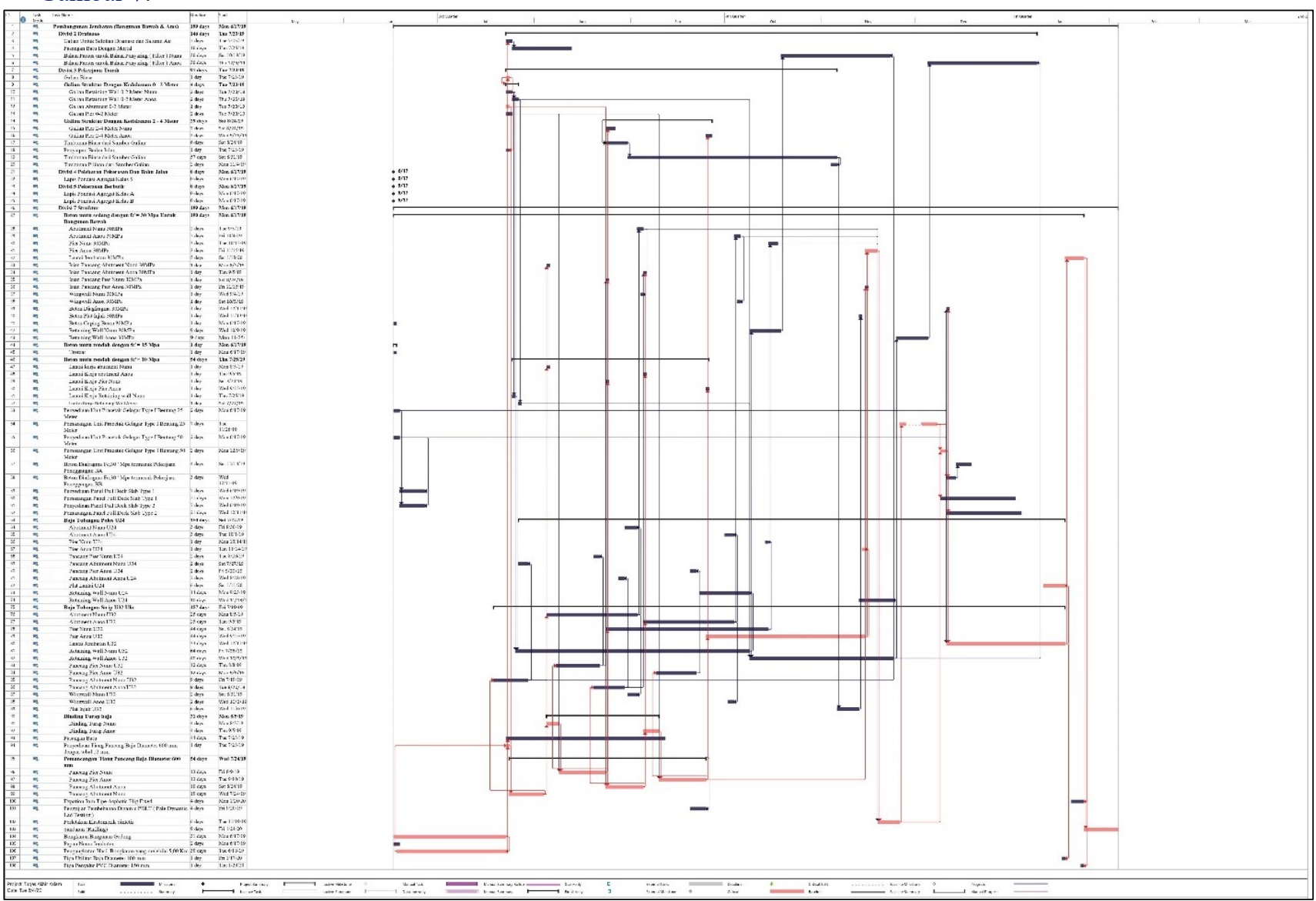

Gambar 7. Tampilan Gannt Chart

\subsection{Aktivitas Kritis dan Durasi Pekerjaan}

Aktifitas kritis yang terjadi pada proyek Jembatan Palu $\mathrm{V}$ setelah dilakukan penjadwalan menggunakan Microsoft Project berada pada bongkaran gedung, penyediaan tiang pancang, pemancangan tiang pancang baja diameter $600 \mathrm{~mm}$, dinding turap baja, baja tulangan U32 ulir, baja tulangan U24 polos, beton mutu sedang fc' $30 \mathrm{MPa}$ untuk bangunan bawah dan bangunan atas, pemasangan unit pracetak gelagar type I bentang 25 dan $50 \mathrm{~m}$ (Gambar 8).

Setelah melakukan pengolahan data di Microsoft project, maka durasi akan otomatis dapat di ketahui dengan cara project $>$ project information $>$ statistics, dapat diketahui jumlah durasi pekerjaan proyek Jembatan Palu V selama 199 hari, terhitung dimulai pekerjaan pada Senin, 17 Juni 2019 dan selesai pada Senin 3 Februari 2020 (Gambar 9).

Pada rescheduling dengan menggunakan Microsoft Project 2019 ini dapat diketahui data data sebagai berikut:

1) Durasi rescheduling sebanyak 199 hari terhitung dari awal pekerjaan hingga pekerjaan beton mutu sedang fc'30 MPa untuk bangunan atas pelat lantai.

2) Pada Network Diagram terdapat pekerjaan atau kegiatan yang kritis yang ditandai dengan garis dan kotak merah. Adapun pekerjaan yang dilalui oleh garis kritis ini adalah pekerjaan yang memiliki pengaruh besar terhadap waktu penyelesaian project ini. Jika ada salah satu saja pekerjaan yang terlambat maka akan berdampak pada pekerjaan lainnya, yang tentu saja berimbas pada terlambatnya penyelesaian project ini secara keseleruhan.

\begin{tabular}{|c|c|c|c|c|c|}
\hline ID & (1) & \begin{tabular}{|l} 
Task \\
Mode
\end{tabular} & Task Name & Duration & Start \\
\hline & & & Pembangun an Jem batan (Bangun an Bawah \& Atas) & 199 days & Mon 6/17/19 \\
\hline 7 & & $\Rightarrow$ & Divisi 3 Pekerjaan Tan ah & 91 days & Tue 7/23/19 \\
\hline 8 & & 5 & Galian Biasa & 1 day & Tue $7 / 23 / 19$ \\
\hline 9 & & 五 & Galian Struktur Dengan Kedalaman 0 - 2 Meter & 4 days & Tue 7/23/19 \\
\hline 12 & & $\bar{G}$ & Galian A butment 0-2 Meter & 1 day & Tue $7 / 23 / 19$ \\
\hline 26 & & - & Divisi 7 Struktur & 199 days & Mon 6/17/19 \\
\hline 27 & & $\overline{5}$ & $\begin{array}{l}\text { Beton mu tu sed ang dengan } \mathrm{fc}^{\prime}=30 \mathrm{Mpa} \text { Un tuk } \\
\text { Bangun an Bawah }\end{array}$ & 190 days & Mon 6/17/19 \\
\hline 31 & & $\bar{F}$ & Pier Anoa $30 \mathrm{MPa}$ & 3 days & Fri $11 / 15 / 19$ \\
\hline 32 & & 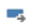 & Lantai Jembatan $30 \mathrm{MPa}$ & 5 days & Sat $1 / 18 / 20$ \\
\hline 54 & & 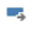 & $\begin{array}{l}\text { Pemasangan Unit Pracetak Gelag ar Type I B entang } 25 \\
\text { Meter }\end{array}$ & 7 days & $\begin{array}{l}\text { Tue } \\
11 / 26 / 19\end{array}$ \\
\hline 56 & & $\Xi$ & $\begin{array}{l}\text { Pemasangan Unit Pracetak Gelagar Type I Bentang } 50 \\
\text { Meter }\end{array}$ & 2 days & Mon 12/9/19 \\
\hline 63 & & 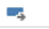 & Baja Tulangan Polos U24 & 150 days & Sat $7 / 27 / 19$ \\
\hline 67 & & $\bar{G}$ & Pier Anc & 1 day & Thu $11 / 14 / 19$ \\
\hline 72 & & $\Rightarrow$ & Plat L antai U 24 & 6 days & Sat $1 / 11 / 20$ \\
\hline 75 & & $=$ & Baja Tulangan Siri & 157 days & Fri $7 / 19 / 19$ \\
\hline 79 & & $\bar{G}$ & Pier A & 44 days & Wed $9 / 25 / 19$ \\
\hline 80 & & $\Rightarrow$ & Lantai Jembatan U 32 & 33 days & Wed $12 / 11 / 1$ \\
\hline 90 & & $=$ & Dinding Turap ba & 31 days & Mon 8/5/19 \\
\hline 91 & & $\overline{7}$ & Dinding Turap Nunu & 4 days & Mon $8 / 5 / 19$ \\
\hline 92 & & 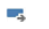 & Dinding Turap Anoa & 4 days & Thu $9 / 5 / 19$ \\
\hline 94 & & $\Xi$ & $\begin{array}{l}\text { Penyediaan Tiang Pancang B aja Diameter } 600 \mathrm{~mm} \\
\text { dengan tebal } 12 \mathrm{~mm}\end{array}$ & 1 day & Tue $7 / 23 / 19$ \\
\hline 95 & & 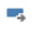 & $\begin{array}{l}\text { Pemancangan Tiang Pancang Baja Diameter } 600 \\
\mathrm{~mm}\end{array}$ & 54 days & Wed $7 / 24 / 19$ \\
\hline 96 & & 5 & Pancang Pier Nunu & 13 days & Fri $8 / 9 / 19$ \\
\hline 97 & & $\bar{G}$ & Pancang Pier Anoa & 13 days & Tue $9 / 10 / 19$ \\
\hline 98 & & 5 & Pancang Abutment Anoa & 10 days & Sat $8 / 24 / 19$ \\
\hline 99 & & 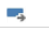 & Pancang Abutment Nunu & 10 days & Wed 7/24/19 \\
\hline 102 & & $\Rightarrow$ & Perletakan Elastomerik Sintetis & 6 days & Tue $11 / 19 / 19$ \\
\hline 103 & & $\Rightarrow$ & Sandaran (Railling) & 9 days & Fri $1 / 24 / 20$ \\
\hline 104 & & $=$ & Bongkaran $B$ angunan $\mathrm{Ged}$ & 31 days & Mon 6/17/19 \\
\hline 106 & & $=$ & Pengangkutan Hasil Bongkaran y ang melebihi $5,00 \mathrm{Km}$ & 30 days & Tue $6 / 18 / 19$ \\
\hline
\end{tabular}

Gambar 8. Aktifitas kritis pada proyek 
Setelah penjelasan diatas terkait data-data yang didapat maka dapat dilihat bahwa dalam rescheduling ini memerlukan waktu lebih lama apabila dibandingkan jadwal rencana dan jika dibandingkan dengan jadwal pelaksanaan dilapangan jadwal rescheduling lebih cepat. Pada jadwal rescheduling yaitu selama 199 hari terhitung dari pekerjaan awal dimulai hingga pekerjaan beton mutu sedang dengan fc'30 MPa untuk bangunan atas pelat lantai. Sedangkan pada time schedule existing rencana proyek yang terlihat pada Lampiran 13 Kurva S rencana durasi yang di butuhkan untuk menyelesaikan beton mutu sedang dengan fc'30 MPa untuk bangunan atas pelat lantai selama 167 hari. Tetapi kenyataan di lapangan pekerjaan mengalami keterlambatan durasi pekerjaan selama 336 hari.

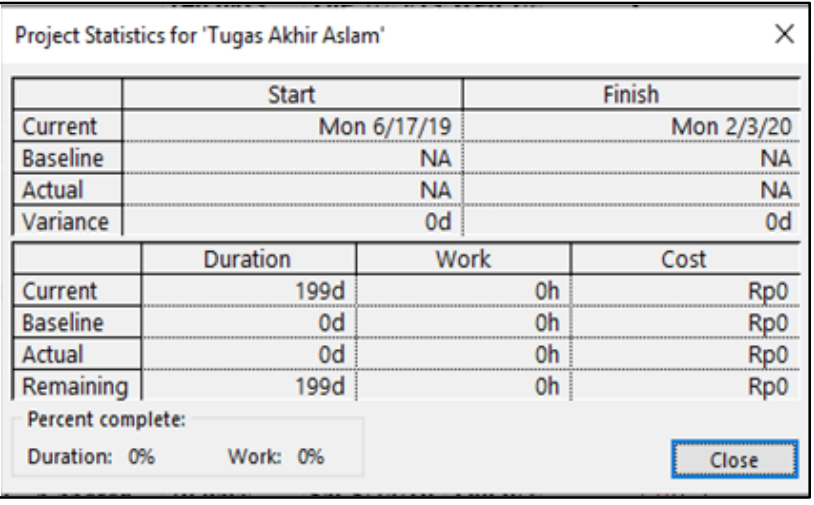

Gambar 9. Tampilan Project Statistic

\section{Kesimpulan}

Kesimpulan yang didapat dari penelitian ini adalah:

1) Durasi waktu yang didapatkan setelah menggunakan Microsoft Project, peneliti memerlukan 199 hari kerja untuk menyelesaikan pekerjaan beton mutu fc'30 MPa untuk bangunan atas pelat lantai.

2) Untuk penjadwalan yang terlaksana dilapangan, pelaksana memerlukan waktu 366 hari kerja untuk menyelesaikan pekerjaan pekerjaan beton mutu sedang dengan fc'30 MPa untuk bangunan atas pelat lantai. Sedangkan penjadwalan yang direncanakan pihak pelaksana memerlukan waktu 167 hari kerja dan durasi waktu yang didapatkan peneliti menggunakan Microsoft Project 199 hari kerja. Jika dibandingkan hasil penjadwalan dengan pihak pelaksanaan dilapangan dan perencanan pelaksana maka hasil yang didapatkan peneliti lebih cepat 167 hari dari waktu pelaksanaan di lapangan dan lebih lambat 32 hari dari durasi waktu perencanaan

\section{Daftar Pustaka}

[1] I. Agustiar and R. Handrianto, "Evaluasi Penjadwalan Proyek Menggunakan Metode CPM dan Kurva S", Wahana Teknik, vol. 7, no. 2, p. 99, 2018.

[2] N.M. Jaya dan A.A.D.P. Dewi, “Analisa Penjadwalan Proyek Menggunakan Rankedpositional Weight Method dan Precedence Diagram Method", Jurnal Ilmiah Teknik Sipil, vol. 11, no. 2, 2007.
[3] Fedrikson, M. Jamal, and F.N. Abdi, "Optimalisasi Biaya dan Waktu Pelaksanaan Proyek Pada Proyek Dengan Metode Least Cost Analysis", Jurnal Teknologi Sipil, vol. 3, no. 1, p. 21, 2019.

[4] T. Tarliah and A. Dimyati, Operations Research : Model-Model Pengambilan Keputusan, Bandung : Sinar Baru Algesindo, 2011.

[5] A.Maddeppungeng, I. Suryani, and M. Iskandar, "Analisis Pengendalian Penjadwalan Pembangunan Gedung Administrasi Universitas Pendidikan Indonesia (UPI) Kampus Serang Menggunakan Metode Work Breakdown Structure (WBS) dan Kurva-S", Jurnal Fondasi, vol. 4, no. 1, p. 88, 2015.

[6] Fachrurrazi, Microsoft Project 2010: Bahas Tuntas Dengan Ribbon, Yogyakarta: Deepublish, 2018.

[7] P. Kelana, Optimalisasi Penggunaan Sumber Daya Manusia Dengan Metode Resource Leveling Menggunakan Bantuan Microsoft Project 2007, Surakarta: Fakultas Teknik Jurusan Teknik Sipil Universitas Sebelas Maret, 2010.

[8] A. Kusrianto, Panduan Lengkap Memakai Microsoft Project 2007, Jakarta: PT. Elex Media Komputindo, 2008.

[9] G.D. Wijaya, Studi Kasus Penjadwalan Proyek Pada Proyek Rumah Toko X Menggunakan Microsoft Project 2010, Surabaya: Fakultas Teknik Jurusan Teknik Sipil Universitas Kristen Petra, 2010.

[10] N.I.M. Muliyadi, Penjadwalan Ulang Proyek Konstruksi Dengan Preseden Diagram Method (PDM) (Studi Kasus Pembangunan Pembangunan Unit Sarana Belajar TK Pembina Kabupaten Kecamatan Johan Pahlawan Kabupaten Aceh Barat), Aceh: Universitas Teuku Umar Meulaboh, 2016.

[11] A. Rezky, Reschedulling Proyek Konstruksi Dengan Menggunakan Software Penjadwalan (Reschedulling Construction Project With Software For Schedulling) (Studi Kasus: Proyek Pembangunan Jalan Nasional Bugel-Galur-Poncosari Tahap 1, Kabupaten Bantul, Yogyakarta: Universitas Islam Indonesia, 2018.

[12] M.I. Setiawan, "Rescheduling Waktu Pekerjaan Guna Optimasi Biaya Pembangunan Rusunawa Siwalan Kerto Surabaya", Neutron, vol. 9, no.1, p. 20, 2009.

[13] S. Tamba and D.M. Hutauruk, "Optimasi Biaya Dan Waktu Akibat Penjadwalan Ulang Pada Proyek Perumahan Menggunakan Microsoft Project", Journal of Civil Engineering, Building And Transportation, vol. 2, no. 1, p. 34, 2018.

[14] Widiasanti, Irika, and Lenggogeni, 2013, Manajemen Konstruksi, Bandung: PT Remaja Rosdakarya, 2003.

[15] S. N. Pratama, "Rescheduling Waktu Pelaksanaan Proyek Pada Pembangunan Gedung SMA Unggulan Samarinda Provinsi Kalimantan Timur", Teknik Sipil dan Arsitektur, vol. 1, no. 1, p. 733, 2016. 